\title{
PROGRAMA GENÉTICA \& SOCIEDADE: ATIVIDADE DE GENÉTICA COMUNITÁRIA COM AÇÕES EM PESQUISA/ ENSINO/EXTENSÃO
}

\author{
Lília Maria de Azevedo Moreira \\ Universidade Federal da Bahia \\ lazevedo@ufba.br
}

Vinícius Magalhães Borges Universidade Federal da Bahia vinyborges@gmail.com

Elaine Regina Jesus Silva Universidade Federal da Bahia lanny_2004@hotmail.com

Wiliane Santos de Oliveira Universidade Federal da Bahia wilioliveira@hotmail.com

Mônica Jacobina Fonseca Vieira Universidade Federal da Bahia monicajacobina@hotmail.com

\author{
Renata Lúcia Leite Ferreira de Lima \\ Universidade Federal da Bahia \\ fdelima@ufba.br
}

Pedro Henrique Silva Andrade Rocha Universidade Federal da Bahia phandrade-1992@hotmail.com

Laís Ribeiro Mota Universidade Federal da Bahia lais_rmota@hotmail.com

Jéssica Fernandes dos Santos Universidade Federal da Bahia fernandess.j@hotmail.com

Lucy Magalhães Freitas Universidade Federal da Bahia lucmf@uol.com.br

\section{Resumo}

Este artigo realiza uma análise de atividades em Pesquisa \Ensino \Extensão do programa de Genética Comunitária Genética \& Sociedade, promovidas no Instituto de Biologia da Universidade Federal da Bahia (UFBA) com o objetivo de levar conhecimentos à comunidade sobre genética e deficiências, preconceitos e exclusão social. A metodologia do trabalho incluiu a realização de atendimentos genéticos, estudo de casos, cariótipos, testes moleculares, aconselhamento genético, oficinas pedagógicas, dinâmicas de grupo, palestras, seminários e outras atividades educativas inclusivas promovidas em instituições especializadas, de financiamento público e $\backslash$ ou filantrópicas. Os resultados obtidos mostram que as ações desenvolvidas constituem estratégias inovadoras e eficazes de popularização da ciência e inclusão de pessoas com deficiências no contexto da família e da sociedade e também ressaltam o papel social da universidade.

Palavras-chave: Programa Genética \& Sociedade. Genética Comunitária. Deficiências. Inclusão. ACCS

\section{GENETICS \& SOCIETY PROGRAM: ACTIVITY OF COMMUNITY GENETIC WITH ACTIONS IN RESEARCH / EDUCATION / EXTENSION}

\begin{abstract}
This article presents an analysis of activities in Research $\backslash$ Education $\backslash$ Extension implemented in the community genetics program Genetics \& Society, Biology Institute of the Federal University of Bahia (UFBA) with the aim of bringing knowledge to the community about genetics and deficiencies, preconceptions and social exclusion. The methodology of study included conducting genetic consultations, case studies, karyotypes, molecular testing, genetic counseling, educational workshops, group dynamics, lectures, seminars and inclusive educational activities promoted in specialized institutions, public finance and $\backslash$ or philanthropic. The results show that the developed actions are innovative and effective strategies for the popularization of science and inclusion of people with disabilities in the context of family and society and also highlight the social role of the university.
\end{abstract}

Keywords: Genetics \& Society Program. Community Genetics. Disabilities. Inclusion. ACCS 


\title{
PROGRAMA GENÉTICA \& SOCIEDAD: ACTIVIDAD DE LA GENÉTICA EN LA COMUNIDAD CON ACCIONES EN LA INVESTIGACIÓN / EDUCACIÓN / EXTENSIÓN
}

\begin{abstract}
Resumen
Este articulo presenta un análisis de las actividades en la Investigación \Educación \Extensión del programa de genética comunitaria "Genética \& Sociedad", promovidas por el Instituto de Biología de la Universidad Federal de la Bahia (UFBA) con el objetivo de llevar conocimientos a la comunidad sobre genética y deficiencias, preconceptos y exclusión social. La metodología del trabajo incluyó la realización de atendimientos genéticos, estudio de casos, cariotipos, ensayos moleculares, asesoramiento genético, talleres pedagógicos, dinámicas de grupo, charlas, seminarios y otras actividades educativas inclusivas realizadas en instituciones especializadas, de financiamiento público y/o filantrópicas. Los resultados obtenidos muestran que las acciones desarrolladas constituyen estrategias innovadoras y eficaces de popularización de la ciencia e inclusión de personas con deficiencias en el contexto de la familia y de la sociedad y también resaltan el papel social de la universidad.

Palabras-claves: Programa Genética \& Sociedad. Genética Comunitaria. Asesoramiento Genético. Deficiencias. Inclusión. ACCS.
\end{abstract}


Programa Genética \& Sociedade: atividade de genética comunitária com ações em pesquisa/ ensino/extensão

\section{INTRODUÇÃO}

O Programa Genética \& Sociedade foi implantado no Instituto de Biologia da Universidade da Bahia (UFBA), tendo em vista complementar as ações realizadas no Laboratório de Genética Humana do referido instituto, trazendo a discussão sobre a naturalidade dos distúrbios genéticos e a importância da investigação científica para o diagnóstico, prognóstico e prevenção desses distúrbios em segmentos da população geral e assim, fortalecendo a interação da universidade com a comunidade geral.

Desde o início da sua criação e funcionando como uma extensão universitária, o Programa Genética \& Sociedade incluiu o estudante nas suas atividades, proporcionando estágios voluntários com prestação de serviços e aprendizado de técnicas citogenéticas ou iniciação científica, com investigação de temas científicos associados à genética.

Em 1995, este programa foi agraciado com o Prêmio Hernani Sobral- Destaque em Extensão na UFBA, pelo conjunto das suas ações englobando atendimentos, orientação genética e realização do estudo de cariótipo, para o reconhecimento de distúrbios cromossômicos, como a Síndrome de Down, além de palestras e cursos, ministrados na universidade ou em diferentes instituições públicas e filantrópicas de educação especial e saúde, em Salvador e no interior do estado da Bahia. Na última década o programa tem dedicado atenção especial a atividades voltadas à inclusão de pessoas com deficiências, passando a promover a interação da extensão com o ensino, com a oferta de Atividades Curriculares em Comunidade e Sociedade (ACCS) em temas da Genética Comunitária, nova disciplina da Genética que promove a divulgação de conhecimentos e tecnologias sobre distúrbios genéticos e genômicos, tendo em vista beneficiar os indivíduos que fazem parte das comunidades e população geral (TEN KATE et al, 2010).

A Ação Curricular em Comunidade e em Sociedade constitui um componente curricular universitário, com carga horária mínima de 17 (dezessete) horas semestrais, modalidade disciplina, nos cursos de Graduação e de Pós-Graduação, em que estudantes e professores da Universidade Federal da Bahia (UFBA), desenvolvem ações em extensão no âmbito da criação, tecnologia e inovação e a produção de conhecimento sobre a realidade, com perspectiva de transformação (Resolução No 01/2013 do CONSEPE).

O componente curricular foi criado na UFBA em 2001, dando continuidade ao Programa UFBA em Campo, proposto em 1996, como modelo de renovação da extensão no viés Universidade e Sociedade, tendo como proposta levar a universidade para fora dos seus muros, podendo atuar em todo o estado da Bahia. Os conteúdos das ACCS se inserem nas diversas áreas de conhecimento e geralmente são abordados de forma interdisciplinar e transdisciplinar 
Programa Genética \& Sociedade: atividade de genética comunitária com ações em pesquisa/ ensino/extensão

com a participação não apenas da equipe universitária, mas também dos profissionais e sujeitos das ações. A associação destas atividades com a prática genética, representa uma forma de preparar novos profissionais com uma visão mais humanitária e também de proporcionar à comunidade externa, a oportunidade de adquirir conhecimentos sobre síndromes genéticas associadas à deficiência intelectual como a S. de Down e do X-Frágil.

O presente trabalho apresenta o objetivo de analisar a contribuição do trinômio: Pesquisa \Extensão \Ensino no Programa Genética \& Sociedade, em ações comunitárias a partir de 2001 quando foram incorporadas as ACCS.

\section{METODOLOGIA}

Estudo descritivo com análise das seguintes ações:

- Atendimentos Genéticos: Estudo de casos, Exames do Cariótipo e Testes Moleculares.

- ACCS- Oficinas Pedagógicas, Dinâmicas de Grupo.

- Palestras, Seminários e outras atividades voltadas para a Inclusão.

Os exames genéticos foram realizados no Laboratório de Genética Humana e Mutagênese (LGHM) que funciona junto com o Programa Genética \& Sociedade no atendimento a comunidade geral.

Os exames citogenéticos eram feitos pelo método convencional de cultura temporária de linfócitos, com tratamento com bandeamento GTG (ISCN, 2013). Os exames moleculares foram realizados partir da extração de DNA genômico, utilizando o kit Genomic Wiz̧ard (Promega), seguindo todas as recomendações do fabricante. As amostras de DNA foram quantificadas e qualificadas através de leitura em espectrofotômetro. Para os diferentes diagnósticos foram desenvolvidas as técnicas de PCR (Reação da Cadeia da Polimerase), MS-PCR (PCR sensível à metilação), corrida eletroforética em gel de agarose e policrilamida.

Os trabalhos das ACCS constituíram atividades de pesquisa-ação, permitindo a identificação de situações-problema referentes à inclusão. Foram também feitos levantamentos, entrevistas e grupos focais (GONDIM, 2003). A pesquisa-ação permite a participação dos usuários na busca de soluções para os seus problemas (THIOLLENT, 1985) e estas são materializadas em intervenções voltadas para a aquisição de conhecimentos e atitudes inclusivas. 
Programa Genética \& Sociedade: atividade de genética comunitária com ações em pesquisa/ ensino/extensão

\section{RESULTADOS E ANÁLISES}

No período compreendido entre 2001 a 2014 foram atendidos pelo programa, indivíduos da população geral no serviço de genética, em busca de orientação e exames genéticos, além de uma demanda adicional proveniente de 2 centros de reabilitação e inclusão para pessoas com deficiência intelectual, 2 moradias para pessoas com deficiências e sem famílias e 3 centros de atenção a idosos, parceiros das ACCS. Esta demanda comunitária extra elevou consideravelmente o número de indivíduos beneficiados não apenas pelos serviços em genética oferecidos no programa como também pelas intervenções educativas.

\section{Atendimentos Genéticos}

Foram atendidos pelo Programa Genética \& Sociedade, 637 indivíduos encaminhados por associações de pessoas com distúrbios genéticos, hospitais, maternidades e instituições especializadas públicas e \ou filantrópicas do estado com solicitações de exames e orientações, em situações de distúrbios genéticos reais ou potenciais (Quadro 1).

\begin{tabular}{|c|c|c|c|}
\hline PERÍODO & $\begin{array}{c}\text { ORIENTAÇÕES } \backslash \\
\text { AVALIAÇÕES }\end{array}$ & CARIÓTIPOS & $\begin{array}{c}\text { EXAMES } \\
\text { MOLECULARES }\end{array}$ \\
\hline 2001 & 53 & 24 & - \\
\hline 2002 & 55 & 25 & - \\
\hline 2003 & 41 & 26 & - \\
\hline 2004 & 34 & 20 & - \\
\hline 2005 & 28 & 14 & - \\
\hline 2006 & 31 & 22 & 23 \\
\hline 2007 & 47 & 30 & 53 \\
\hline 2008 & 46 & 35 & 65 \\
\hline 2009 & 36 & 22 & 55 \\
\hline 2010 & 61 & 27 & 48 \\
\hline 2011 & 84 & 41 & 32 \\
\hline 2012 & 64 & 52 & 286 \\
\hline 2013 & 54 & 40 & 27 \\
\hline 2014 & 39 & 405 & -1014 \\
\hline TOTAL & 673 & & - \\
\hline
\end{tabular}

Quadro 1 - Atendimentos genéticos realizados pelo programa no período 2001-1014. 
Programa Genética \& Sociedade: atividade de genética comunitária com ações em pesquisa/ ensino/extensão

A partir de 2008 foram introduzidos os testes moleculares na metodologia de avaliação de distúrbios genéticos, começando com a Síndrome do X-Frágil (SXF). Em 2009, o laboratório iniciou o diagnóstico para mutação $\Delta$ F508 da doença Fibrose Cística (FC) e no ano de 2013 para as alterações nos padrões de metilação relacionados às Síndromes de Prader-Willi (SPW) e Angelman (SA). As frequências das alterações encontradas no período foram de 13,4\% (em 175 casos investigados para SXF), 20,65\% (em 92 casos de FC) e 33,33\% (em 18 casos de SPW e AS). O percentual de 33\% de cromossomopatias foi verificado no período delimitado no presente estudo com a ocorrência de 135 casos com alterações cromossômicas em amostra de 405 indivíduos. Este resultado corrobora a investigação citogenética de período anterior, abrangendo 813 indivíduos atendidos no laboratório, que também indicou 33\% de alterações cromossômicas (MOREIRA et al, 2011). Entre estas ocorreram 117 indivíduos com a Síndrome de Down, aneuploidia autossômica mais prevalente (MOREIRA et al, 2011). A avaliação atual inclui casos de S. Down, S. Patau, S. Edwards, Klinefelter, S. Turner, Trissomia do X e outras alterações citogenéticas sutis e reafirma a importância das cromossomopatias na etiologia da deficiência intelectual e malformações congênitas.

Alguns dos estudos realizados subsidiaram a elaboração de dissertações, trabalhos científicos, relatórios e parcerias institucionais, com a realização gratuita de exames avançados. Os trabalhos publicados seguiram as normas bioéticas da obtenção do consentimento informado das famílias, de acordo com as resoluções $196 \backslash 96$ e 466\12, preconizadas pelo Conselho Nacional de Saúde.

Os atendimentos proporcionaram a identificação de síndromes e a orientação continuada às famílias. Estas famílias eram também convidadas a participar de palestras e outros eventos educativos que pudessem contribuir para a reabilitação e $\backslash$ ou inclusão (MOREIRA et al, 2010).

\section{Atividades de Educação Continuada e ACCS}

Atividades extensionistas em Genética voltadas para a comunidade, já eram realizadas pelo Programa Genética \& Sociedade do Instituto de Biologia da UFBA desde a sua fundação na década de 90. Entre os serviços em Genética Comunitária, praticados no Laboratório de Genética Humana e Mutagênese (LGHM) e oferecidos a instituições especializadas no atendimento a pessoas com deficiências, incluía-se além de exames genéticos, orientação a famílias com histórico de distúrbios genéticos, palestras e seminários. Com a criação das ACCS, atividades curriculares com temáticas da Genética Comunitária, passaram a ser oferecidas 
Programa Genética \& Sociedade: atividade de genética comunitária com ações em pesquisa/ ensino/extensão

semestralmente a estudantes de diferentes cursos de graduação, desde 2001 até o presente (Quadro 2), com turmas de 10 a 12 alunos em cada semestre letivo.

\section{ACCS BIO 456- Genética e diversidade humana EMENTA:}

Estudos sobre as interações entre a Genética e o ambiente e suas consequências sociais. Formas de variação genética humana associada à inclusão social. Trabalho com crianças com deficiências, vítimas de preconceitos, no sentido de promover o respeito à diversidade e a cidadania. A inclusão na escola e na sociedade. PERÍODO: 2001.2 -2009.2

\section{ACCS BIO A94- Inclusão: contribuições da Genética e da Educação} EMENTA:

Estudo sobre a variação genética associada à diversidade humana nas diferentes

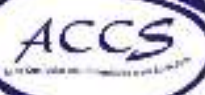

fases da vida. Intervenções biomédicas. Visão histórico/social da deficiência. Deficiência e cidadania. Atividades educativas na desconstrução de preconceitos e promoção da inclusão. PERÍODO: 2010.1 a 2014.2

Quadro 2 - ACCS em Genética Comunitária associadas ao Programa Genética \& Sociedade realizadas na UFBA no período de 2001 a 2014. Fonte: Elaborado pelos autores, 2015.

As Atividades Curriculares em Comunidade e Sociedade (ACCS) constituem inciativas pioneiras da Universidade Federal da Bahia com enfoque no ensino, pesquisa e extensão. As atividades voltadas a Genética Comunitária foram incluídas no calendário das ACCS desde o segundo semestre do ano de sua implantação em 2001, com ações propostas pelos alunos que compunham a equipe de trabalho ou por demandas solicitadas pelas instituições atendidas, tendo em vista intervir em situações-problemas previamente levantadas.

No Quadro 3 são descritas as situações \demandas e as ações elaboradas como forma de intervenção. As figuras 1 e 2 apresentam atividades realizadas pelas referidas ACCS. 
Programa Genética \& Sociedade: atividade de genética comunitária com ações em pesquisa/ ensino/extensão

\begin{tabular}{|l|l|}
\hline \multicolumn{1}{|c|}{ SÍNTESE DAS DEMANDAS } & \multicolumn{1}{c|}{ ESTRATÉGIAS \AÇÕES } \\
\hline $\begin{array}{l}\text { Necessidade de esclarecimentos em Genética e } \\
\text { Desenvolvimento }\end{array}$ & Palestras, Seminários, Dinâmicas de grupo. \\
\hline $\begin{array}{l}\text { Conhecimentos sobre envelhecimento e e } \\
\text { deficiências }\end{array}$ & Palestras, Seminários, Dinâmicas de grupos. \\
\hline Respeito para com a pessoa com deficiência. & $\begin{array}{l}\text { Oficinas pedagógicas, Dinâmicas, de grupo, } \\
\text { Campanhas educativas. }\end{array}$ \\
\hline Aprendizado de convivência social & Oficinas pedagógicas, Dinâmicas de grupo. \\
\hline $\begin{array}{l}\text { Esclarecimentos sobre temas em Sexualidade e e } \\
\text { Reprodução }\end{array}$ & Palestras, Seminários, Dinâmicas de grupo. \\
\hline $\begin{array}{l}\text { Oportunidades de socialização } \\
\text { Reforço na compreensão do papel social das } \\
\text { famílias }\end{array}$ & $\begin{array}{l}\text { Atividades inclusivas em espaços de lazer, } \\
\text { Oficinas pedagógicas. }\end{array}$ \\
\hline Valorização do lazer na Inclusão & Oficinas de Arte e Educação. \\
\hline Reforço da autoestima & Oficinas pedagógicas, Dinâmicas de grupo. \\
\hline Educação continuada & Palestras, Seminários, Feira de Ciência. \\
\hline
\end{tabular}

Quadro 3 - Intervenções realizadas pelo grupo ACCS em diferentes semestres letivos de 2001 a 2014.

Fonte: Elaborado pelos autores, 2015.

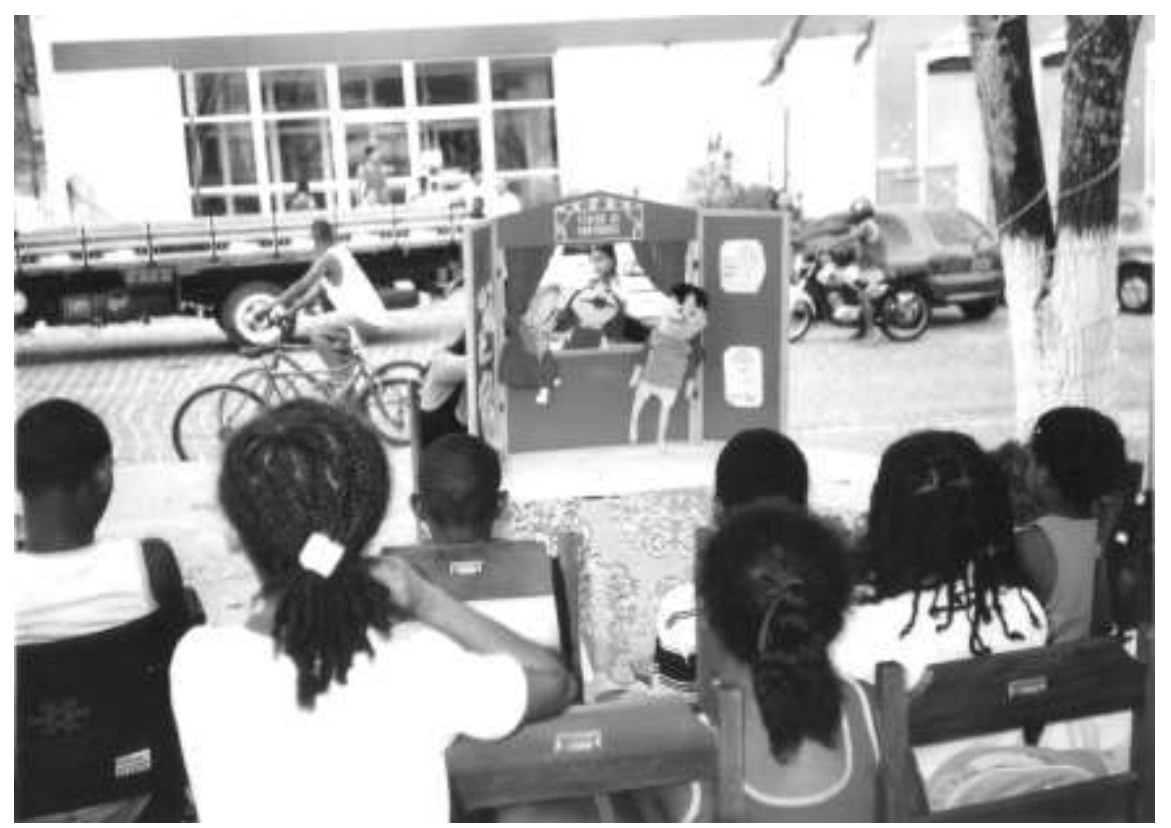

Figura 1 - Atividade lúdica com teatro de bonecos em ação comunitária voltada para a popularização da ciência.

Fonte: Autoria dos autores, 2015. 
Programa Genética \& Sociedade: atividade de genética comunitária com ações em pesquisa/ ensino/extensão

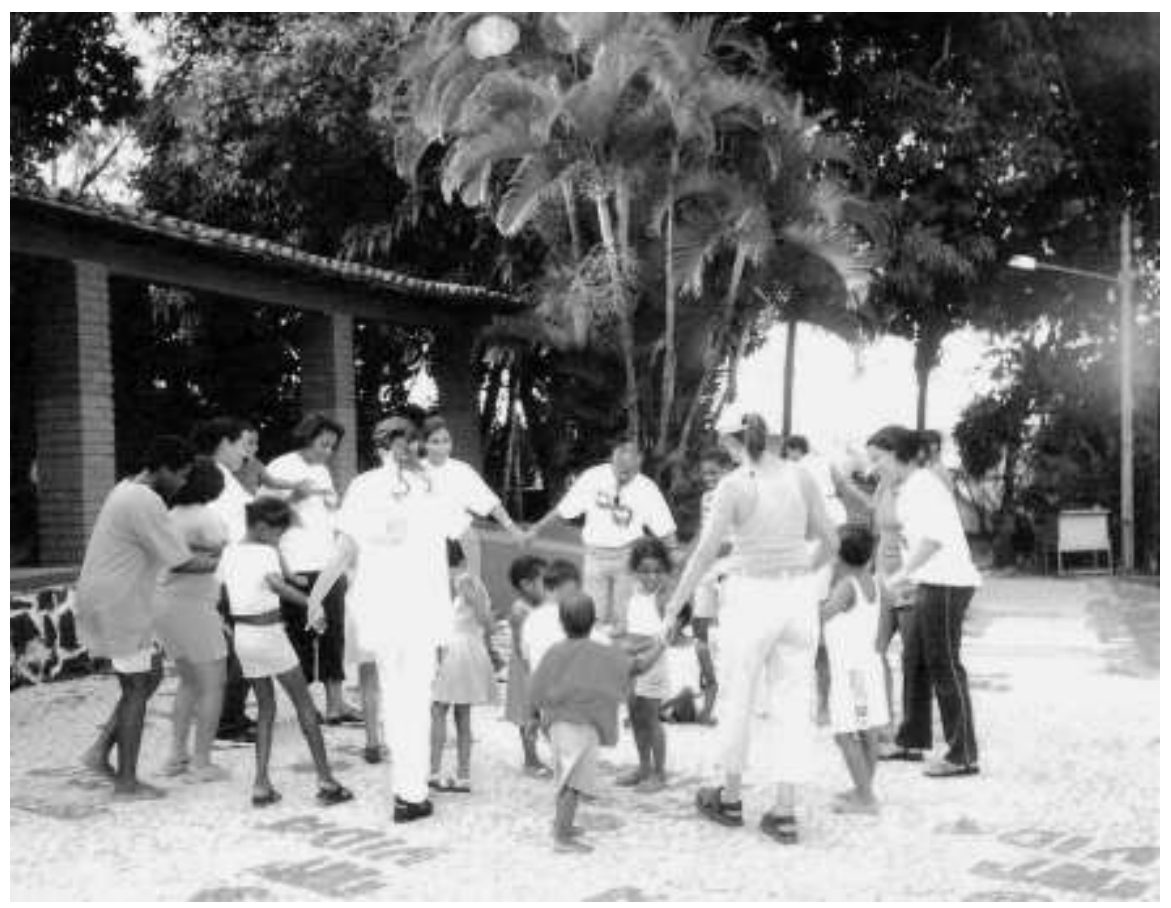

Figura 2 - Atividade inclusiva em instituição de acolhimento e moradia para pessoas com deficiências.

Fonte: Autoria dos autores, 2015.

A Genética é uma ciência nova que apresenta grandes desafios decorrentes de avanços tecnológicos e influência de fatores sócio \culturais na interpretação dos seus paradigmas. Concepções errôneas, eivadas de mitos estão ainda presentes no cotidiano de famílias com histórico de distúrbios genéticos. Os serviços de genética constituem o espaço adequado para esclarecimentos, quebra de preconceitos e compreensão de modelos atuais sobre a origem e transmissão de características hereditárias. No Aconselhamento Genético os indivíduos buscam respostas para questionamentos que os mobilizam emocionalmente, tentando achar explicações sobre o porquê do nascimento do seu filho com algum distúrbio genético (SANTOS, 2005).

A realização de exames genéticos laboratoriais como a cariotipagem constitui importante instrumento de investigação etiológica, dada a associação entre as cromossomopatias e a deficiência intelectual e o prognóstico mais favorável obtido com a intervenção precoce. $\mathrm{Na}$ espécie humana, ocorrem cromossomopatias em $0,6 \%$ dos nascidos vivos e deste percentual, a maioria são alterações numéricas, como é o caso da trissomia 21 (S.Down) (MOREIRA et al, 2011).

Duarte et al (2004), referem que embora as alterações cromossômicas estejam incluídas entre as mais importantes causas de morbi \mortalidade na América Latina (OPS, 1984), tais desordens ainda recebem cuidados insuficientes por parte de poderes públicos.

Sob este prisma, a Genética Comunitária inclui no seu escopo, a missão de contribuir para a mudança de atitudes sociais por meio da informação e educação de profissionais e população 
Programa Genética \& Sociedade: atividade de genética comunitária com ações em pesquisa/ ensino/extensão

geral em questões genéticas. O programa de trabalho das ACCS abrange estas premissas e contribui para a educação continuada de profissionais e usuários das atividades realizadas semestralmente.

Como outras disciplinas, a Genética Comunitária tem aspectos científicos e práticos (RAMALHO e SILVA, 2000). A carência de conhecimentos científicos na população geral é um fator que contribui para a existência de crenças e preconceitos, o que justifica a necessidade de programas educativos que levem à popularização desta ciência. Intervenções educativas realizadas no âmbito das atividades curriculares, sobre a etiologia do distúrbio, importância de tratamentos e da aceitação na família e na sociedade, têm trazido benefícios significativos às crianças com Síndrome de Down e com outros diversos distúrbios, através do Programa Genética \& Sociedade. O acompanhamento destes casos mostra taxas elevadas de adesão a programas terapêuticos e educativos e mudanças comportamentais na família e entorno social.

A popularização do conhecimento, decorrente das ações do programa, tem propiciado benefícios não apenas à comunidade atendida pelo Programa Genética\&Sociedade, mas também a estudantes, técnicos e docentes participantes, em termos de produção científica e realização do compromisso social da universidade pública e gratuita.

\section{CONSIDERAÇÕES FINAIS}

As atividades relatadas neste estudo evidenciam que as intervenções em Genética Comunitária desenvolvidas pelo Programa Genética \& Sociedade, com ações em Pesquisa/Ensino/Extensão, constituem estratégias inovadoras e eficazes de contribuição para a inclusão de pessoas com deficiências no contexto da família e da sociedade.

A interação da ciência com a educação em programas comunitários demonstra que o conhecimento pode estar ao alcance de todos e ressalta o papel social da universidade, principalmente a pública, em se tratando de um retorno as expectativas e carências comuns a sociedade. 
Programa Genética \& Sociedade: atividade de genética comunitária com ações em pesquisa/ ensino/extensão

\section{AGRADECIMENTOS}

Os autores agradecem aos monitores e alunos da ACCS, aos participantes do Programa Genética \& Sociedade, às pessoas atendidas, famílias, profissionais e instituições pelo apoio e por acreditarem na importância do trabalho realizado.

\section{REFERÊNCIAS}

CONSELHO SUPERIOR DE ENSINO, PESQUISA E EXTENSÃO: Resolução no 01\2013. Regulamento do aproveitamento da Ação Curricular em Comunidade e em Sociedade, Salvador, 2013.

DUARTE, A.C.; CUNHA, E.; ROTH, J.M.; FERREIRA, F.L.S.; GARCIAS, G.L.; MARTINOROTH, M.G. Cytogenetics of genetic counseling patients in Pelotas. Rio Grande do Sul, Brasil, Genetics and Molecular Research, v.3, n.3, 2004, p. 303-308.

GONDIM, S.M.G. Grupos Focais como técnica de investigação qualitativa: desafios metodológicos. Paidéia, v. 12, n. 24, 2003, p. 149-161.

MOREIRA, L.M.A.; CABANELAS, I.T.D.; CARVALHO, M.S.; GALVÃO, J.P. A educação continuada e de um novo olhar sobre a Síndrome de Down. Extensio: R.Eletr.de Extensão, n.9, 2010, p.144-153.

MOREIRA, L.M.A.; ESPIRITO SANTO, L.D.; RODRIGUES, M.O.; SANTOS, T.O; CABANELAS, I.T.D.; FARIAS, J.O.; LIMA, R.L.L.F. Alterações cromossômicas em 813 atendimentos em Genética Comunitária, Revista de Ciências Medicas e Biológicas, v. 10, n. 1, 2011, p. 26-28.

ORGANIZATION PANAMERICANA DE LA SALUD (OPS). Prevencion y Control de las Enfermedades Geneticas y los Defectos Congenitos. Publicacion Cientifica No460, Washington, DC, USA, 1984.

RAMALHO, A.S.; SILVA, R.B.P. Community Genetics: a new discipline and its application in Brazil. Cad. Saude Publica, v. 16, 2000, p. 261-263.

SANTOS, S. Para geneticistas e educadores: o conhecimento cotidiano sobre herança biológica. São Paulo, Annablume, 2005, p. 154. 
Programa Genética \& Sociedade: atividade de genética comunitária com ações em pesquisa/ ensino/extensão

SHAFFER, L.G.; MCGOWAN-JORDAN, J. SCHMIDT, M, editores. ISCN (2013): An international system for human cytogentic nomenclature. Editora Karger, 2013, p. 140.

TEN KATE, L. P.; AL-GAZALI, L.; ANAND, S.; CHRISTIANSON, A.; CORNEL, M. C.; HAMAMY, H.; KÄ̈̈RIÄINEN, H.; KRISTOFFERSSON, U.; MARAIS, D.; PENCHASZADEH, V. B.; RAHMAN, P; SCHMIDTKE, J. Community genetics. Its definition. J Community Genet, v. 1, 2010, p. 19-22.

THIOLLENT, M. Metodologia de pesquisa-ação. São Paulo: Cortez, 1985, p. 107. 